УДК 61.614.614.2

\title{
ПРОЦЕССНЫЕ ТЕХНОЛОГИИ ФОРМИРОВАНИЯ АЛГОРИТМА УПРАВЛЕНИЯ НОВОЙ МОДЕЛЬЮ МЕДИЦИНСКИХ ОРГАНИЗЦИЙ
}

Царик Галина Николаевна д.м.н., профессор, заведующая кафедрой общественного здоровья, здравоохранения и медицинской информатики

ФГБОУ «Кемеровский государственный медицинский университет»

Рытенкова Ольга Леонидовна

к.м.н., руководитель, Региональный центр организации первичной медико-санитарной помощи ГБПОУ «Кузбасский медицинский колледж»

Грачева Татьяна Юрьевна д.м.н., доц., заместитель главного врача по медицинской части ГБУЗ Кузбасская клиническая психиатрическая больница

Аннотация. В статье рассмотрены различные аспекты повышения качества и доступности медицинской помощи посредством создания процессной модели деятельности и алгоритма управления развитием медицинских организаций с использованием бережливых технологий, что обеспечило сокращение временных потерь пациентами при получении медицинской помощи и повышение эффективности использования ресурсов медицинских организаций.

Ключевые слова: процессная модель медицинской организации, алгоритм управления повышением качества медицинской помощи.

\section{PROCESS TECHNOLOGIES FOR FORMING AN ALGORITHM FOR MANAGING A NEW MODEL OF MEDICAL ORGANIZATIONS}

\section{Tsarik Galina Nikolaevna Rychenkova Olga Leonidovna Gracheva Tatyana Yurievna}

Abstract. The article considers various aspects of improving the quality and accessibility of medical care by creating a process model of activity and an 
algorithm for managing the development of medical institutions using lean technologies, which reduced the time losses of patients receiving medical care and increased the efficiency of using the resources of medical organizations.

Keywords: process model of a medical organization, algorithm for managing the improvement of the quality of medical care.

Введение. Повышение качества и доступности медицинской помощи основная цель политики государства в области охраны здоровья граждан Российской Федерации. Качество и доступность медицинской помощи остаются важнейшими проблемами отечественного здравоохранения. Актуальность их решения обусловлена опережающим уровнем требований населения к системе, призванной гарантировать сохранение наиболее значимой человеческой ценности - здоровья, и реальными возможностями отрасли [1, с.52; 2, с.29].

Социальная значимость проблемы качества и доступности медицинской помощи особенно резко возрастает в условиях социально-экономических преобразований, развития рыночных отношений, в том числе частного сектора здравоохранения.

Основополагающая цель современного здравоохранения - повышение удовлетворенности пациентов качеством и доступностью медицинской помощи.

Совершенствование управления развитием медицинских организаций (MO) предлагается осуществлять на основе бережливых технологий оказания услуг, обеспечивающих ликвидацию очередей, сокращение продолжительности пребывания пациентов в стационаре, повышение эффективности использования ресурсов [3, с. 18; 4, с.210].

С целью повышения эффективности оказания медицинских услуг на амбулаторном этапе Министерством здравоохранения Российской Федерации рекомендовано внедрение технологий бережливого производства и тиражирование «Новой модели организации, оказывающей первичную медико-санитарную помощь».

С августа 2018 г. в Кузбассе стартовал федеральный проект «Развитие системы оказания первичной медико-санитарной помощи». Планом по внедрению «Новой модели медицинской организации», утвержденным Министерством здравоохранения Российской Федерации внедрение бережливых технологий в поликлиниках предполагается увеличить с 2 в 2018 г. до 168 в 2024 г. 
Правительством Российской Федерации поставлены амбициозные задачи перед здравоохранением - 70\% всех поликлиник должны стать «бережливыми» к 2025 году, в том числе все детские поликлиники достичь «базового» уровня к 2021 году.

Реализация бережливых технологий позволит обеспечить доступность и оказание качественной медицинской помощи при имеющихся ограниченных финансовых и кадровых ресурсах в условиях дефицита помещений за счет:

- сокращения всех видов потерь (ожидание, брак, перепроизводство, ненужная транспортировка, лишние движения),

- обеспечения равномерного сбалансированного распределения функциональных обязанностей между врачами и средним медперсоналом,

- формирования рациональных потоков пациентов в зависимости от цели посещения медицинской организации,

- эффективного использования площади МО,

- оптимизации информационных потоков, в т.ч. повышения эффективности медицинской информационной системы,

- стандартизации лечебно-диагностических процессов на базе «лучших практик» и снижение их вариабельности.

Применение технологий бережливого производства в медицинских организациях дает возможность за счет снижения потерь и рациональной организации работы эффективнее использовать имеющиеся ресурсы [5, с. 83].

Достижение критериев «Новой модели поликлиники» требуют выявления процессов, нуждающихся в совершенствовании и реализации проектов, направленных на их улучшение.

Цель исследования. Разработка процессной модели деятельности и алгоритма управления развитием медицинской организации.

Материал и методы исследования. Объект исследования механизма управления представлен 94 медицинскими организациями первичной медико-санитарной помощи, внедряющими бережливые технологии. Для изучения текущего состояния доступности, удовлетворенности и качества медицинской помощи применялся метод непосредственного наблюдения и хронометража продолжительности получения пациентами медицинских услуг. Предусматривалось проведение анкетирования потока пациентов, обратившихся за медицинской помощью и медицинского персонала, обеспечивающего оказание помощи. Исследованием охвачено 610 пациентов, 460 врачей и 430 средних медицинских работников. Сбор 
информации проводился с учетом информированного согласия респондентов. Вопросы анкеты позволяли оценить информацию по направлениям: материально-техническая база организации; доступность медицинской помощи; качество медицинских услуг; культура медицинского обслуживания; уровень справочной наглядной информации; порядок и чистота; лекарственное обеспечение; удовлетворенность пациентов медицинским обслуживанием; проблемы организации с точки зрения пациентов и сотрудников организации; желание пациентов сменить организацию для прикрепления по системе обязательного медицинского страхования и участкового врача; структура обращения пациентов в медицинскую организацию и потребность в помощи; возможность и доступность обращения в другие медицинские организации; виды услуг недоступных для пациентов.

Для обеспечения оптимизации управления на основании материалов, характеризующих текущее состояние доступности, удовлетворенности и качества медицинской помощи предполагалось формирование процессной модели организации, включая классификатор видов деятельности. Применение матрицы системного анализа, таблицы MS Excel и гиперссылок способствовало определению приоритетов и разработке проектов по улучшению, что обеспечило формирование алгоритма управления развитием организации.

В соответствии с федеральным законом «Об основах охраны здоровья граждан в Российской Федерации» от 21.11.2011 № 323-Ф3, «ГОСТ Р ИСО 9001-2015. Национальный стандарт Российской Федерации. Системы менеджмента качества. Требования» - утв. Приказом Росстандарта от 28.09.2015 № 1391-ст вместе с «Разъяснением новой структуры, терминологии и понятий», «Другими международными стандартами в области менеджмента качества и системы менеджмента качества, разработанными ИСО/ТК 176»; Программой государственных гарантий бесплатного оказания гражданам медицинской помощи; объемными и финансовыми показателями деятельности организаций, изучения текущего состояния доступности, удовлетворенности и качества медицинской помощи Институтом социальноэкономических проблем здравоохранения разработана процессная модель поликлиники (Рис. 1).

Процессная модель включает:

- процессы жизненного цикла медицинской помощи;

- управленческие процессы; 


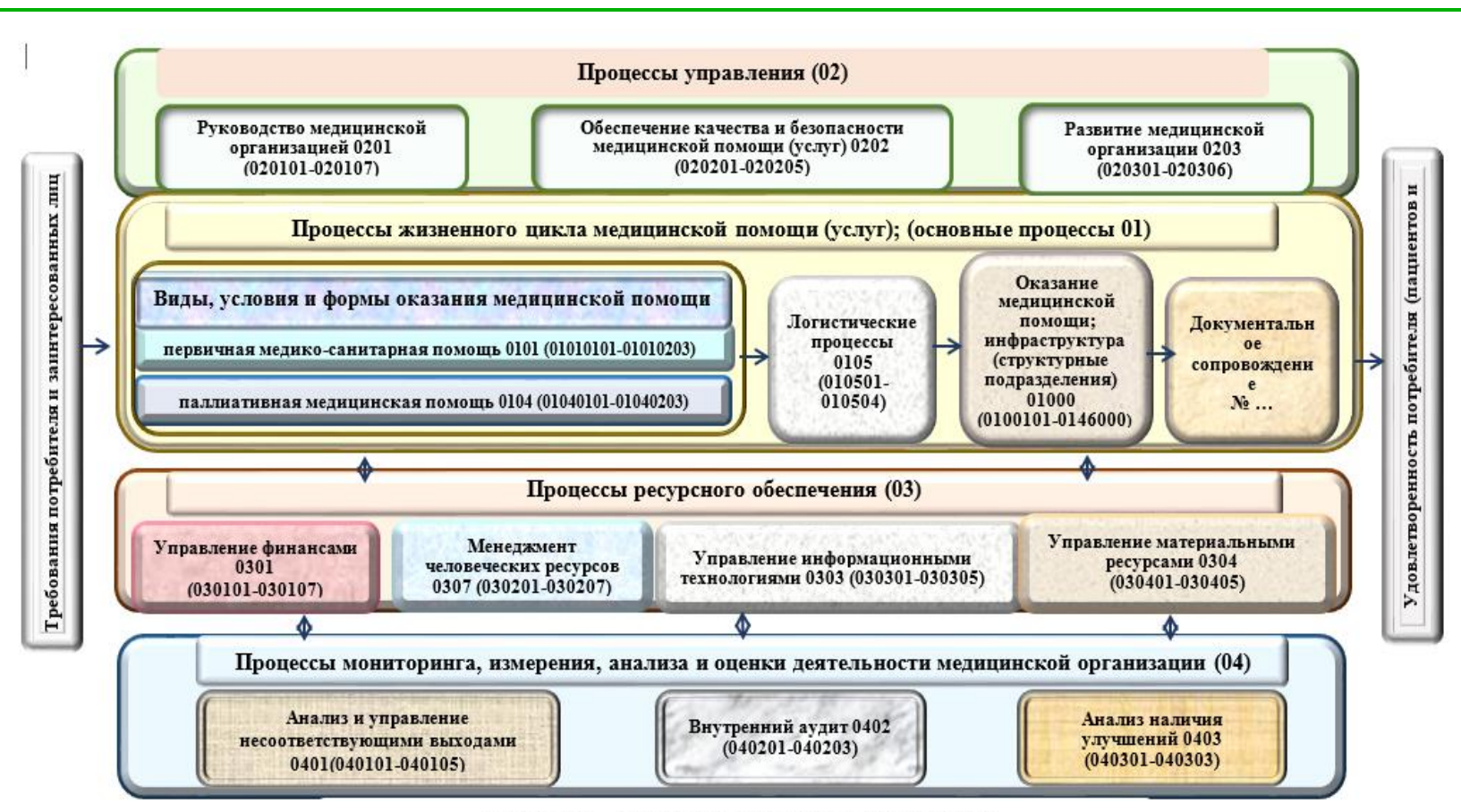

Рисунок 1 - Процессная модель поликлиники

- процессы ресурсного обеспечения;

- процессы мониторинга, измерения, анализа и оценки деятельности медицинской организации.

Улучшение отдельно взятых процессов не позволяет оценить динамику и степень достижения критериев «Новой модели поликлиники», создать целостную картину её развития.

В связи с этим возникла потребность в создании инструмента, позволяющего осуществлять разработку долгосрочного проекта развития организации, проведение мониторинга в режиме on- line, контроль сроков реализации проектов и принимать управленческие решения в оперативном режиме с использованием информационных технологий.

Сотрудниками Кемеровского государственного медицинского университета, Института социально-экономических проблем здравоохранения, Регионального центра организации первичной медикосанитарной помощи и Регионального центра компетенций Кемеровской области на основании проведенного анкетирования и хронометража продолжительности получения медицинской помощи разработана система управления развитием медицинских организаций с использованием бережливых технологий (СУРМО).

Алгоритм управления развитием медицинской организации сформирован посредством:

- определения миссии организации, ее цели и задач; 
- разработки процессной модели деятельности организации и классификатора процессов;

- обоснования и разработки проекта развития организации на долгосрочный период.

Проект развития организации включает:

- открытие и паспорт проекта;

- оценку ситуации;

- картирование сплошного потока пациентов;

- анализ проблем и потерь;

- составление карты целевого и идеального состояния;

- разработку плана мероприятий;

- порядок представления проекта;

- внедрение улучшений;

- мониторинг результатов;

- этапную оценку достижений;

- мониторинг стабильности результатов.

Мониторинг достижений долгосрочного проекта предусматривает этапную оценку выполнения запланированных мероприятий. Завершением считается достижение ожидаемого результата с мониторингом его стабильности.

Составной частью долгосрочного проекта являются лин-проекты, направленные на улучшение процессов и решение наиболее актуальных проблем.

СУРМО позволяет в автоматическом режиме строить в соответствии с данными хронометража карты текущего и целевого состояний, диаграмму Ганта (план мероприятий), осуществлять мониторинг сроков реализации мероприятий. Содержит блоки последовательных действий в соответствии с этапами открытия и реализации проекта, включающих: теоретическую часть (по каждому из разделов), документы для практического использования (Рис. 2).

Оптимизация управления развитием медицинской организации достигается посредством размещения алгоритма в таблице MS Excel и использования гиперссылок, содержащих образцы документов, необходимых для реализации проекта и обеспечивающих:

- унификацию технологий управления процессами и возможность использования в любой сфере, 


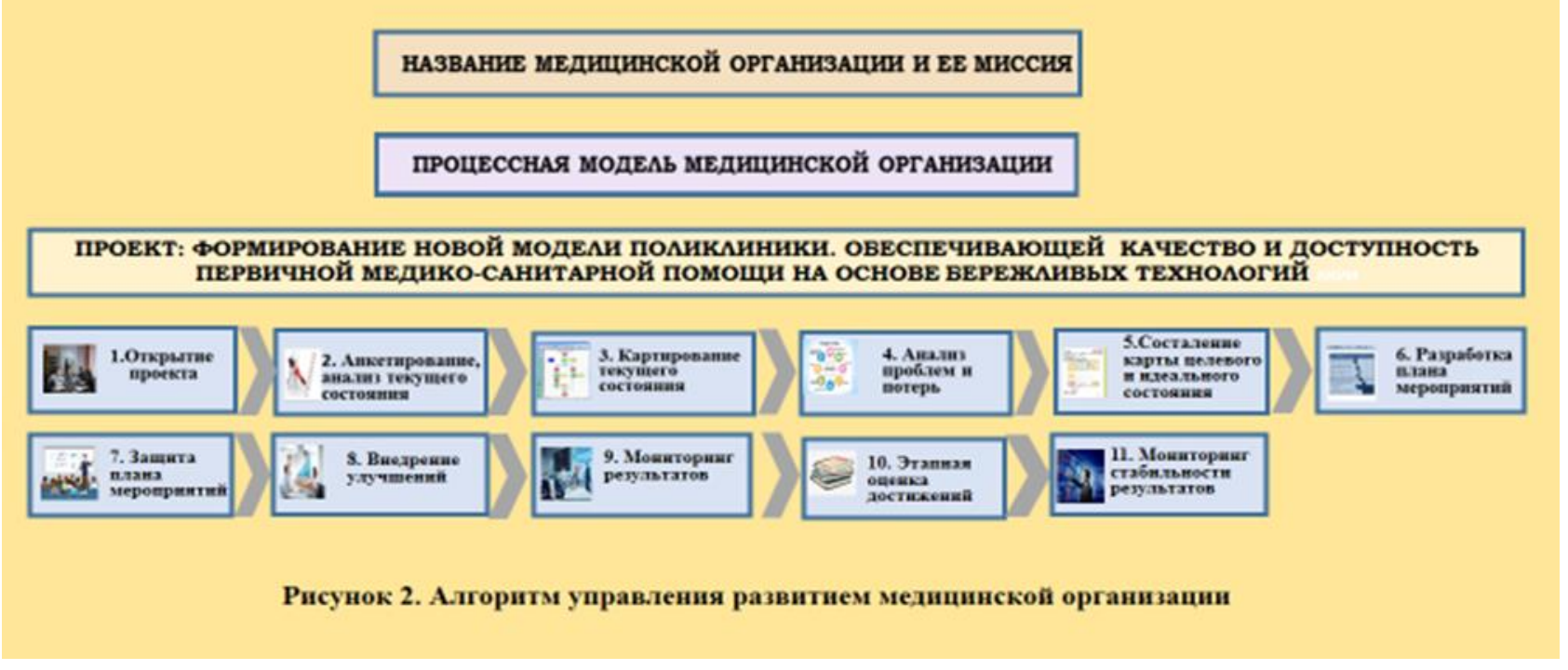

- сокращение временных ресурсов на оформление и визуализацию проекта улучшения за счет автоматизации процессов (построение карт текущего и целевого состояний, диаграммы Ганта, разработки нормативных документов),

- повышение оперативности принятия управленческих решений с учетом результатов мониторинга в режиме on-line.

В настоящее время в Кузбассе реализуется 502 лин-проекта улучшений с использованием представленных выше технологий по направлениям:

- работа поликлиник в условиях covid-19,

- проведение первого этапа диспансеризации;

- направление пациентов на госпитализацию;

- вакцинопрофилактика;

- работа процедурного кабинета;

- управление запасами;

- профилактический осмотр несовершеннолетних;

- постановка беременной на диспансерный учет и др.

Результаты исследования. Реализация проектов способствовала:

- сокращению времени прохождения профилактического осмотра детей в 5 раз с 5,1 до 1,0 дня $(\mathrm{P}=0,001)$,

- уменьшению продолжительности первого этапа диспансеризации в 1,5 раза с 3,0 до 2,0 дней $(\mathrm{P}=0,005)$,

- сокращению ожидания вакцинации в 2,6 раза с 45 мин. до 17,3 мин. $(\mathrm{P}=0,001)$; 
- сокращению ожидания забора анализов и проведения инъекций в 5 раз с 87,5 мин до 17,5 мин $(\mathrm{P}=0,001)$;

- повышению удовлетворенности населения работой регистратуры на $46 \%$ с $41 \%$ до $87 \%$ ( $\mathrm{P}=0,004)$;

- снижению простоя оборудования в физиотерапевтических отделениях на $30 \%$ с $50 \%$ до $20 \%(\mathrm{P}=0,003)$.

Обсуждение. Изучение проблемы обеспечения доступности и качества медицинской помощи, развития профилактического направления, повышения эффективности деятельности медицинских организаций не теряет актуальности, так как имеется ряд существенных проблем и недостатков, требующих решения [5, с. $82 ; 6$, с.99].

В литературе широко обсуждаются проблемы отрасли и предлагаются различные варианты решений [7, с. 43; 8, с. 602; 9, с.616]. Особую значимость приобретает оптимизация процессов управления медицинскими организациями с использованием компьютерных технологий [10, с. 465; 11, с. 688]. Важное место отводится повышению эффективности обмена информацией между врачами и средним медицинским персоналом [12, 13, с. 138].

Однако использование процессного подхода в управлении медицинскими организациями с применением компьютерных технологий и бережливого производства в литературе представлено недостаточно.

В публикации представлен механизм оптимизации управления развитием медицинских организаций на основе процессного подхода и бережливых технологий посредством реализации лин-проектов и формирования новой модели организации первичной медико-санитарной помощи.

В ходе реализации проектов выявлялись и решались проблемы:

1. Недостаточные знания основ бережливого производства;

2. Низкая мотивация сотрудников медицинских организаций к внедрению бережливых технологий;

3. Дефицит кадров;

4. Недостаточно активное тиражирование проектов;

5. Ограничительные мероприятия, связанные с неблагоприятной эпидемиологической обстановкой в связи с COVID-19.

Недостаток знаний основ бережливого производства восполнялся посредством мероприятий по коррекции ситуации с участием специалистов Госкорпорации РОСАТОМ, Минздрава России, учебных заведений Кузбасса, Регионального центра первичной медико-санитарной помощи и 
Регионального центра компетенций Кузбасса включая обучение более 500 работников медицинских организаций; открытие 5 фабрик процессов, в том числе «Доврачебный прием», «Процедурный кабинет», «5С», «Проведение совещания с использованием SQDCM», «Диспансеризация», тренинг «Направление на плановую госпитализацию»; издание учебного пособия «Обеспечение качества и доступности медицинской помощи посредством повышения эффективности управления организациями системы здравоохранения на основе ГОСТ Р ИСО 9001:2015» [14, с. 216] и организацию тестирования ответственных за внедрение бережливых технологий.

В целях мотивации сотрудников медицинских организаций к внедрению бережливых технологий организовывались регулярные экскурсии в поликлиники, наиболее успешно внедряющие бережливые технологии и имеющих опыт лучших практик. Важное место отводилось стимулированию сотрудников в рамках реализации проектов.

Проблема дефицита кадров решалась путем разработки и реализации проектов, позволяющих использовать внутренние резервы, сокращать потери времени и простой оборудования.

Коррекция недостаточно активного тиражирования проектов проводилась с применением разработки «коробочных решений» и создания классификатора проектов улучшений, реализованных в медицинских учреждениях региона, на основе перечня критериев достижения «Новой модели организации, оказывающей первичную медико-санитарную помощь».

Ограничительные мероприятия, связанные с неблагоприятной эпидемиологической обстановкой в связи с COVID-19 обусловили переход на дистанционный формат консультирования, обучения, проведения аудита с использованием видео лекций по инструментам бережливого производства, рассмотрением и согласованием в дистанционном режиме 179 паспортов линпроектов по улучшениям.

Результаты лин-проектов доказали эффективность проведенных мероприятий.

С 2020 года реализация проектов улучшений, мониторинг достигнутых результатов осуществляется с использованием СУРМО, что способствует переходу от отдельных проектов - к единой модели поликлиники [5, с. 83].

Заключение. Разработка процессной модели, классификатора деятельности и алгоритма управления развитием медицинской организации способствовала сокращению временных потерь пациентами при получении 
первичной медико-санитарной помощи, повышению эффективности использования оборудования, что подтверждает достижение цели исследования. Представленные организационные технологии рекомендуется использовать для управления развитием медицинских организаций.

\section{Список литературы}

1. Князюк Н. Управление качеством. Пошаговый алгоритм, чтобы перейти на новую версию ИСО 9001:2015 $\rightarrow$ 52/ Н. Князюк // Здравоохранение. Журнал для управления медицинской организацией. Москва: ООО «МЦФЭР», № 9 сентябрь 2017. - С. 51-65.

2. Решетников В.А. Коршевер Н.Г., Доровская А.И. Компетентный подход к подготовке специалистов в области управления здравоохранением. Сеченовский вестник 2016; 2(24): 27-32.

3. Вялков А.И. Сквирская Г.П. Логистические исследования в управлении здравоохранением. Принципы построения и реализации дорожных карт. Менеджер здравоохранения. 2015: (22): 13-9.

4. Писарев С.Л. Рауцкий О.Е. Информатизация в здравоохранении, как аналитическая основа поддержки управленческих решений. В кн.: Материалы $\mathrm{V}$ Международной научно-практической конференции «Проблемы управления социально-экономическими системами: теория и практика». Тверь; 2017. С.209-212.

5. Царик Г.Н., Грачева Т.Ю., Алешина А.А., Ткачева У.С. Правовые аспекты и процессные модели повышения качества и доступности помощи в медицинских организациях. Медицинское право: теория и практика. Москва, Т.4 № 2 (8). С 81-85.

6. Свидерская Л.Н., Симакова В.М., Хендогина В.Т., Чавкунькин Ф.П. Опыт организации процесса контроля качества в условиях краевой консультативной поликлиники // Сибирское медицинское обозрение. 2015 №3(93). С 97-101.

7. Слободский Г.В., Хаткевич М.И., Шутова С.А. Оптимизация процесса госпитализации в медицинские организации третьего уровня медицинской помощи с использованием процессного подхода //Врач и информационные технологии. 2015. №4. С. 43-50.

8. Коршевер Н.Г., Помошников С.Н., Доровская А.И. Оценка успешности принятия управленческих решений в медицинских организациях. Проблемы социальной гигиены, здравоохранения и истории медицины. - M, T.28 Vol. 28; 2020 №4. С 600-604. 
9. Журавлев С.В., Колодкин А.А., Максимов Д.А. Трофименко А.В., Дежурный Л.И., Бояринцев В.В. Организация учета частоты, объема и результативности мероприятий первой помощи. Проблемы социальной гигиены, здравоохранения и истории медицины. - M, T.28 Vol. 28; 2020 №4. C 616-620.

10. Amudha P., Hamidah H., Annamma K., AnanthN. Effektive communication detween nurses. Res. Artikle J. Nurs. Care. 2018; 7 (3): 465. Doi: 104172/2167-2168.1000455.

11. Goncalves L.A.P., Mendonca A.L.O., Camargojunior K.R. The interaction between doctors and nurses in the context of a hospital ward. Clen Saude Colet. 2019; 24 (3): 683-692 doi; 10.1590/1413 - 812 32018243.32162016.

12. Schirle L., McCabe B.E., Mitrani V. The relationship between practice environtment and psihological ownership in advance praktike nurses. West J. Nurs. Res. 2018; 019394591875479. Doi: 10 1177/0193945918754499.

13. Bochattay A. Are role persept ofions reridens and nurses translated into action?. BMC Med. Educat. 2017; 17;138, doi; 10 1186/s 12909-017-0976-2.

14. Обеспечение качества и доступности медицинской помощи посредством повышения эффективности управления организациями системы здравоохранения на основе ГОСТ Р ИСО 9001:2015 и ресурсосберегающих технологий (бережливого производства) /под ред. Г.Н. Царик // Учебное пособие. - 2-е изд. доп. и перераб. - Кемерово, 2019. - 315 с. 